\title{
Protocolo ajustado a segundo nivel de atención para trasplante renal de donante vivo, experiencia en supervivencia en un centro del Instituto Mexicano del Seguro Social
}

\author{
Protocol adjusted to second level kidney transplant care living donor, \\ experience in survival in an Instituto Mexicano del Seguro Social Center
}

\author{
Daniela Radilla-Ramos,* Gilberto Rojas-Hernández, ${ }^{\ddagger}$ Saúl Barajas-González, \\ Liliana Espinosa-Mercado," José Salvador Sandoval-Quintanađ \\ * Universidad Vasco de Quiroga, Campus Santa María, Morelia, Michoacán, México. \\ ‡ Departamento de Cirugía y Trasplante Renal. Programa de Trasplante Renal. Hospital General \\ Regional No. 1, Delegación Michoacán, Instituto Mexicano del Seguro Social, Charo, Michoacán, México. \\ $\S$ Departamento de Nefrología. Programa de Trasplante Renal. Hospital General Regional No. 1, \\ Delegación Michoacán, Instituto Mexicano del Seguro Social, Charo, Michoacán, México. \\ " Departamento de Trabajo Social. Hospital General Regional No. 1, Delegación \\ Michoacán, Instituto Mexicano del Seguro Social, Charo, Michoacán, México. \\ " Universidad Michoacana de San Nicolás de Hidalgo. Facultad de Ciencias Médicas \\ y Biológicas «Dr. Ignacio Chávez», Morelia, Michoacán, México.
}

\begin{abstract}
RESUMEN
Introducción: La insuficiencia renal crónica terminal (IRCT) es un problema de grandes dimensiones en México. Se habla de una población total de alrededor de 174 mil enfermos en 2016, sin embargo, a la fecha, no se cuenta con información precisa, pues no existe en México un registro nacional centralizado de casos de padecimientos renales. El trasplante renal es la terapia de reemplazo de elección en la mayoría de los pacientes con IRCT. Material y métodos: Se realizó un estudio descriptivo, ambispectivo, durante el periodo comprendido de julio de 2014, fecha del primer trasplante, a diciembre de 2019. Se revisaron los expedientes clínicos físicos y electrónicos de los pacientes. Se analizó la supervivencia del injerto y del paciente en trasplante renal de donador vivo a uno, tres, seis, 12, 24, 36, 48 y 60 meses (cinco años), mediante curvas de supervivencia actuarial de Kaplan-Meier. Resultados: Durante el periodo se realizaron 65 trasplantes renales de donador vivo, todos trasplantes primarios, $65 \%$ hombres $(\mathrm{n}=42)$ y 23 mujeres (35\%), con edad promedio de $26.53 \pm 8.08$ (rango 17-53). La supervivencia global del paciente fue de $98 \%$ a cinco
\end{abstract}

\begin{abstract}
Introduction: End-stage renal failure (ESRD) is a large problem in Mexico. There is talk of a total population of around 174 thousand patients in 2016, however, to date, there is no precise information, since there is no centralized national registry of cases of kidney disease in Mexico. Kidney transplant is the replacement therapy of choice in most patients with ESRD. Material and methods: A retrospective-prospective longitudinal and observational study was carried out during the period from July 2014, the date of the first transplant, to December 2019. The physical and electronic clinical files of the patients were reviewed. We analyzed the survival of the graft and the patient with kidney transplant from living donor at 1 , $3,6,12,24,36,48$ and 60 months (five years), using KaplanMeier actuarial survival curves. The results obtained were compared with those obtained in living donor of third level hospitals. Results: During the period, 65 living donor kidney transplants were performed, all primary transplants, $65 \%$ men $(n=42)$ and 23 women (35\%), with an average age of 26.53 \pm 8.08 (range 17-53). The patient's overall survival was $98 \%$
\end{abstract}


años. La supervivencia del injerto fue de $98 \%$ a dos años y $94 \%$ a cinco años. Se reportaron sólo cuatro pérdidas del injerto: una por trombosis arterial, otra por rechazo crónico humoral, una más por rechazo crónico por falta de consumo de medicamentos inmunosupresores y la última por defunción del receptor renal, a uno, 26, 28 y 34 meses, respectivamente. Conclusión: Nuestros resultados evidencian que la supervivencia del paciente y del injerto en un hospital de segundo nivel son equiparables con los hospitales de tercer nivel. La selección de pacientes en este tipo de unidades médicas es importante, por los recursos y la infraestructura con la que se cuenta; por lo que trabajar sobre pacientes con bajo riesgo inmunológico garantiza una mejor tasa de éxito en ambas supervivencias y, por consecuencia, una mejor calidad de vida.

Palabras clave: Trasplante renal, segundo nivel, supervivencia

\section{INTRODUCCIÓN}

La falla renal es un problema de salud a nivel mundial, junto con los efectos adversos de ésta: la pérdida de la función renal, la enfermedad cardiovascular y la muerte prematura. Así como el incremento en la incidencia y prevalencia, los altos costos y los pobres resultados.

La epidemia de la enfermedad renal crónica (ERC) es global. Los efectos adversos son universales, así como lo son la ciencia subyacente y las estrategias basadas en evidencia para la prevención, detección, evaluación y su tratamiento. ${ }^{1}$

Las enfermedades crónicas se encuentran entre las principales causas de muerte a nivel mundial. La Organización Mundial de la Salud (OMS) estima que hubo aproximadamente 58 millones de muertes en el mundo en 2005, con 35 millones atribuidas a enfermedades crónicas. El informe de la OMS, en ese año, pidió a los gobiernos que brindaran liderazgo para abordar el proyectado continuo aumento de muertes por enfermedades crónicas. ${ }^{2}$

Los países que han experimentado la prevalencia de incrementos absolutos más grandes en enfermedad renal terminal desde 2000/2001 incluyen a México (Jalisco) (de 270 a 1,654 por millón de habitantes [pmh]), la República de Corea (de 142 a 585 pmh), Chile (de 612 a 1,294 pmh), Malasia (de 338 a 1,140 pmh) y Tailandia (de 98 a 1,097 pmh). ${ }^{3}$

Como se reporta, la ERC es también un problema de grandes dimensiones en México. Desafortunadamente, a la fecha, no se cuenta con información precisa, pues no existe un registro nacional centralizado de casos de padecimientos renales de gran valor para su caracterización, determinación de incidencias y prevalencias, análisis de costos, planeación de acciones y at five years. Graft survival was $98 \%$ at two years and $94 \%$ at five years. Only four graft losses were reported: one due to arterial thrombosis, another due to chronic humoral rejection, one more due to chronic rejection due to lack of consumption of immunosuppressive drugs and the last due to death of the renal receptor, at 1, 26, 28 and 34 months, respectively. Conclusion: Our results show that the survival of the patient and the graft in a second level hospital are comparable with third level hospitals. The selection of patients in this type of medical units is important, due to the resources and the infrastructure that is available; therefore, working on patients with low immunological risk guarantees a better success rate in both survivals and consequently, a better quality of life.

Keywords: Kidney transplant, second level, survival.

recursos, ya que muchas de las verdaderas causas de muerte que serían atribuibles a la enfermedad, en su progresión desde las etapas tempranas, se reportan como muertes por enfermedades cardiovasculares. A pesar del subregistro, fuentes oficiales citan a la ERC dentro de las primeras diez causas de mortalidad general en el último decenio.

En 2016, se podría hablar de alrededor de 124 mil enfermos en todo México ( $2 \%$ del total de personas adultas con ERC, sólo por diabetes) que requirieron de alguna de las terapias sustitutivas o restitutivas, como son la diálisis peritoneal, la hemodiálisis y/o trasplante renal. Para etapas tardías, 4 y 5 (insuficiencia renal crónica [IRC] e insuficiencia renal crónica terminal [IRCT]), es indiscutible el uso de modelos de atención más complejos, equipamiento especializado, fármacos, insumos y recursos humanos altamente capacitados para ejecutar los tratamientos que son imprescindibles en el aseguramiento de una mayor y mejor supervivencia de los pacientes.

El Instituto Mexicano del Seguro Social (IMSS) tiene, en 2016, registrados poco más de 60 mil enfermos en terapia sustitutiva, 25 mil de los cuales (41.7\%) están en un programa de hemodiálisis y alrededor de 35 mil reciben servicios de diálisis peritoneal (58.3\%). De los enfermos en hemodiálisis, la gran mayoría son atendidos por contrato multianual (cuatro años) de subrogación de servicios en unidades privadas extramuros $(70 \%)$ y un número menor $(30 \%)$ por medio de servicios internos en unidades propias (intramuros).

Se estima que el IMSS otorga $80 \%$ de todas las diálisis a nivel nacional, el ISSSTE $8 \%$, SSA y privados $5 \%$ y el resto del sector $7 \%$, lo cual quiere decir que sólo 74,400 enfermos de los 124 mil (en etapas 4 y 5 por diabetes) reciben tratamiento sustitutivo. Del 
resto no se conoce nada. Si a este total de diabéticos en etapas 4 y 5 se les suma aquellos casos sólo con hipertensión y por otras causas (40\%), hablaríamos entonces de una población total de alrededor de 174 mil enfermos, tan sólo hasta 2016.

De este total de 124 mil enfermos con insuficiencia renal crónica e insuficiencia renal crónica terminal por diabetes (etapas 4 y 5), 60\% podría permanecer de por vida en alguna de las dos modalidades de la diálisis, ya que no calificaría para recibir un trasplante y, por tanto, estos pacientes serían los menos afortunados; $20 \%$, dadas las condiciones de salud más aceptables que las de otros, podría ser sometido a un trasplante anticipado sin requerir diálisis previa; y el resto, $20 \%$, requerirá de diálisis como manejo preparatorio de al menos seis meses antes de ser sometido a un trasplante. ${ }^{4}$

De acuerdo al Centro Nacional de Trasplantes (CENATRA), en el estado de Michoacán, se tienen registrados, hasta diciembre de 2017, un total de 2,439 pacientes con ERC terminal. Además, hasta diciembre de 2019 se tenían registrados un total de 17,069 pacientes con enfermedad renal crónica terminal que califican para un trasplante renal en México. ${ }^{5}$

A nivel mundial se realizaron un total de 91,815 trasplantes de riñón, reportados en el año 2018; de los cuales 36,541 se realizaron en América, y de éstos, 3,048 en México. Las cifras que presenta el CENATRA para este 2020 continúan siendo desalentadoras y comprenden apenas un total de 2,939 casos (trasplantes renales realizados en 2019), de los cuales, 1,511 se realizaron en el IMSS, de una lista de 17,069 pacientes en espera de un riñón a nivel nacional. Del total de los trasplantes realizados en el IMSS, 1,071 $(71 \%)$ proviene de donadores vivos relacionados y sólo una minoría, 440 (29\%), de donadores cadavéricos. ${ }^{5,6}$

El trasplante renal es la terapia de reemplazo de elección en la mayoría de los pacientes con enfermedad renal crónica en etapa avanzada (4 y 5 Kidney Disease Outcomes Quality Initiative [KDOQI]) y que requieren tratamiento sustitutivo de la función renal. Un trasplante exitoso se asocia con mejoría en la supervivencia, mejoría en la calidad de vida y, sin lugar a dudas, en importantes disminuciones de costos en salud en comparación con cualquier modalidad de diálisis. $^{7}$

El trasplante renal de donante vivo se asocia con mejores resultados que el trasplante renal de donante fallecido, independientemente de la relación genética existente entre donante y receptor. ${ }^{8}$ Son múltiples los factores que han contribuido a mejorar la supervivencia del injerto y del paciente; entre los más importantes se mencionan una mayor compatibilidad entre el donante y el receptor, el uso de nuevas drogas inmunosupresoras, las transfusiones específicas pretrasplante, un seguimiento más organizado del paciente y un manejo oportuno de las múltiples complicaciones postrasplante, el tiempo de isquemia, edad del donante y receptor, sexo, peso, talla, IMC, entre otras. ${ }^{9,10}$

El rechazo es una de las complicaciones más temidas en el trasplante. La incidencia global es de $5-10 \%$, aunque puede tener una incidencia mayor, en torno de $35 \%$, en el grupo de alto riesgo inmunológico, de prevalencia creciente. ${ }^{11}$

Los registros existentes en distintos países han confirmado una progresiva mejoría de los resultados del trasplante a corto plazo. En la actualidad, la incidencia de rechazo agudo es menor a $15 \%$ y la supervivencia del injerto es mayor a $90 \%$ al año del tratamiento. ${ }^{12}$

Las diferencias evolutivas incluyen mejoras, no sólo en términos de supervivencia del injerto, sino también en la supervivencia del paciente. Los datos del Organ Procurement Transplant Network demuestran que la supervivencia del injerto renal a cinco años es de $79.7 \%$ para los receptores de donante vivo frente a $66.5 \%$ para los de donante fallecido, y la supervivencia del paciente a cinco años es de $90.1 \%$ frente a $81.9 \%$. Los datos del Collaborative Transplant Study ofrecen

Tabla 1: Características basales de receptores de trasplante renal de donante vivo en el Hospital General Regional No. 1, Charo, Michoacán.

\begin{tabular}{lcc}
\hline \multicolumn{1}{c}{ Donador vivo } & Recuento & $\%$ \\
\hline Género & & \\
Femenino & 23 & 35 \\
Masculino & 42 & 65 \\
Grupo sanguíneo & & \\
O positivo & 37 & 57 \\
A positivo & 21 & 32 \\
B positivo & 5 & 8 \\
AB positivo & 2 & 3 \\
Terapia de reemplazo renal & & 8 \\
Prediálisis & 5 & 54 \\
Diálisis peritoneal & 35 & 38 \\
Hemodiálisis & 25 & 26 \\
Transfusiones sanguíneas & & 74 \\
Sí & 17 & \\
No & 48 & 65 \\
Embarazo & & \\
Sí & 8 & \\
No & 15 & \\
\hline
\end{tabular}


Tabla 2: Características basales de receptores de trasplante renal de donante vivo en el Hospital General Regional No. 1, Charo, Michoacán.

\begin{tabular}{lllc}
\hline Donador vivo & \multicolumn{1}{c}{$\begin{array}{c}\text { Media } \\
\text { (Rango) }\end{array}$} & $\begin{array}{c}\text { Desviación } \\
\text { típica }\end{array}$ \\
\hline Edad receptor & Total & $26.53(17-53)$ & 8.08 \\
& Femenino & $25.78(17-42)$ & 5.99 \\
& Masculino & $26.95(17-53)$ & 9.06 \\
Terapia de & Diálisis peritoneal & $18.45(3-120)$ & 20.98 \\
reemplazo & Hemodiálisis & $23.12(2-72)$ & 21.97 \\
renal (meses) & & & \\
Transfusiones sanguíneas & $3.4(1-9)$ & 2.42 \\
(por paquete globular) & & \\
Embarazos (por número de gestas) & $1.875(1-4)$ & 1.125 \\
\hline
\end{tabular}

resultados muy similares a los del registro americano. ${ }^{8}$

En cuanto a México, el CENATRA, hizo referencia a un estudio de Hernández-Jiménez JD, del año 2012, acerca de la supervivencia global del paciente trasplantado renal a un año de $94.9 \%$, a tres años de $93.4 \%$ y a cinco años de $82.3 \%$. La supervivencia global del injerto fue de $87.6 \%$ a un año, de $79.7 \%$ a tres años y de $61.5 \%$ a cinco años. ${ }^{13}$

Más reciente, en un estudio de Martínez-Mier G y colaboradores, de 2016, se reportaron, a partir del análisis de 95 trasplantes (43 de donante vivo y 52 de fallecido), la supervivencia global del paciente al año de $94.7 \%$, a los cinco años de $85.2 \%$ y a los 10 años de $77.9 \%$. La supervivencia global del injerto de $87.2 \%$ al año, de $59.7 \%$ a los cinco años y de $43.8 \%$ a los 10 años, respectivamente. ${ }^{14}$

Como se observa, las supervivencias reportadas, tanto para injerto renal como para paciente postrasplantado renal, son estudiadas y reportadas a partir de centros hospitalarios de tercer nivel. Sin embargo, es muy poca la literatura en la que se estudian los centros hospitalarios o unidades médicas de segundo nivel de atención a la salud.

El Hospital General Regional No. 1 del Instituto Mexicano del Seguro Social (IMSS), de Charo, Michoacán, es un centro hospitalario de segundo nivel de atención. Se había iniciado en 1993 un programa de trasplante renal en el que se realizaron ocho procedimientos quirúrgicos entre 1993 y 1994. Éstos se realizaron bajo el impulso de los nefrólogos del mismo hospital con el apoyo quirúrgico del CMNO, Jalisco. Se reinicia el programa en 1997, año en el cual se reorganiza el Comité de Trasplantes. El programa funciona hasta el año 2001, realizándose en ese tiempo 44 trasplantes de donador vivo-relacionado. Diversos factores, entre los que destaca la falta de asig- nación de un presupuesto específico para esta actividad, interrumpen nuevamente el programa de trasplante renal de este hospital. Sin embargo, a través de una suma de logros y esfuerzos, a finales de 2004 vuelve a ponerse en funcionamiento. ${ }^{15}$ Con el fin de mejorar la calidad de atención al derechohabiente, se construye un nuevo edificio, moviendo esta atención del municipio de Morelia a Charo, Michoacán, con lo que se pierde nuevamente la licencia sobre el Departamento de Trasplante Renal en 2010, por cambio de domicilio, reiniciando el programa en 2014 que continúa hasta nuestros días.

Con lo mencionado, esta investigación plantea estudiar el programa de trasplante renal y conocer la supervivencia del injerto y del paciente postrasplantado renal de un hospital de segundo nivel, en este caso, del Hospital General Regional No. 1, Charo, Michoacán; con la finalidad de comparar y demostrar las supervivencias mencionadas y la similitud que existe entre estas y los hospitales de tercer nivel o de alta especialidad.

\section{MATERIAL Y MÉTODOS}

Se realizó un estudio descriptivo, ambispectivo de los pacientes sometidos a trasplante renal de donador vivo relacionado y no-relacionado en el Hospital General Regional No. 1 de Charo, Michoacán, durante el periodo comprendido del 09 de julio de 2014, fecha del primer trasplante, a diciembre de 2019. El proyecto de investigación fue aprobado por el Comité Local de Investigación en Salud-1602; con el folio número F-20181602-18 y número de registro R-2018-1602-015.

Se revisaron los expedientes clínicos de los pacientes, tanto físicos como electrónicos, con análisis de notas médicas y resultados de laboratorio y gabinete. Se analizaron y registraron las siguientes variables sociodemográficas: género, edad, lugar de origen y

Tabla 3: Características de los trasplantes renales de donante vivo realizados en el Hospital General Regional No. 1, Charo, Michoacán.

\begin{tabular}{lcc}
\hline Donador vivo & Recuento & $\%$ \\
\hline Total trasplantes & 65 & 100 \\
Tipo de donador vivo & & \\
Relacionado & 50 & 77 \\
No relacionado & 15 & 23 \\
Histocompatibilidad (haplotipos compartidos) & \\
O haplotipos & 15 & 23 \\
1 haplotipo & 45 & 69 \\
2 haplotipos & 5 & 8 \\
\hline
\end{tabular}


grupo sanguíneo. Se registraron también las variables relacionadas con el trasplante, tales como etiología de insuficiencia renal crónica, tiempo en diálisis o hemodiálisis (meses) pretrasplante, histocompatibilidad (haplotipos compartidos con donador) y tipo de donante.

Los criterios de inclusión para los receptores y donadores en el Programa de Trasplante Renal del Hospital General Regional No. 1, IMSS, Charo, Mich., se mencionan en la Tabla 1.

Con parámetros de eficacia del programa se evaluó la supervivencia tanto del paciente como del injerto a cinco años, así como causas de pérdidas del injerto.

Se definió como pérdida del injerto a la disminución de la depuración de creatinina por debajo de $15 \mathrm{~mL} /$ min, calculada por la fórmula de MDRD o el ingreso a terapia de reemplazo renal (hemodiálisis o diálisis peritoneal), además de la mortalidad del receptor renal.

Se analizó la supervivencia del injerto y del paciente en trasplante renal de donador vivo sea relacionado o no-relacionado a uno, tres, seis, $12,24,36,48$ y 60 meses (cinco años), mediante curvas de supervivencia actuarial de Kaplan-Meier.

El análisis estadístico fue llevado a cabo emplean- do medidas de tendencia central, a través de media, mediana, desviación estándar y porcentajes/proporciones tanto para variables escalares como categóricas, además de las curvas de Kaplan-Meier para análisis de ambas supervivencias.

\section{RESULTADOS}

Durante el periodo de julio de 2014 a diciembre de 2019 se realizaron 65 trasplantes de donador vivo, todos trasplantes primarios, siendo en su mayoría a hombres; los datos sobre edad, grupo sanguíneo y transfusiones sanguíneas presentadas durante el padecimiento se presentan en la Tabla 2.

Sobre el lugar de origen de los pacientes, Morelia se encuentra en primer lugar, seguido de Ciudad Hidalgo (Figura 1).

Por otro lado, 57 pacientes (88\%) tenían etiología desconocida de su IRCT, seguida por cuatro pacientes (6\%) con hipertensión arterial sistémica, tres pacientes con poliquistosis renal (4\%) y un paciente con glomeruloesclerosis focal y segmentaria (2\%). Sólo cinco pacientes $(8 \%)$ fueron trasplantados antes de someterse

Tabla 4: Criterios de inclusión para los receptores y donadores en el Programa de Trasplante Renal del Hospital

General Regional no. 1, Instituto Mexicano del Seguro Social, Charo, Michoacán.

Receptor

\begin{tabular}{|c|c|}
\hline Receptor & Donador vivo \\
\hline Edad: de 16 a 55 años & Edad: de 18 a 55 años \\
\hline Índice de masa corporal menor de 30 kg/m2 & Índice de masa corporal menor de 30 kg/m2 \\
\hline No hepatitis B o C & No hepatitis B o C \\
\hline Citomegalovirus inactivo & Citomegalovirus inactivo \\
\hline No malformaciones estructurales o funcionales de las vías urinarias & No malformaciones estructurales o funcionales de las vías urinarias \\
\hline No diabetes mellitus & No más de dos vasos (arterias o venas renales) mostrados en angiotomografía \\
\hline No insuficiencia hepática avanzada & No enfermedades crónicas \\
\hline No cardiopatías, no insuficiencia cardiaca severa o refractaria & No cardiopatías \\
\hline $\begin{array}{l}\text { No alto riesgo inmunológico: multitransfusiones, trasplantes previos, pruebas } \\
\text { cruzadas previas positivas, terapia sustitutiva de función renal de larga evolución, } \\
\text { cuadros de peritonitis previos }\end{array}$ & No patologías agregadas \\
\hline No alteraciones de la circulación arterial y/o venosa & Compatibilidad de grupo sanguíneo \\
\hline Compatibilidad de grupo sanguíneo & $\begin{array}{l}\text { Pruebas cruzadas pretrasplante negativas con el receptor, así como porcentaje de } \\
\text { reactividad de anticuerpos (PRA) bajo }\end{array}$ \\
\hline \multicolumn{2}{|l|}{ Contar con seguridad social } \\
\hline \multicolumn{2}{|c|}{ Contraindicaciones absolutas } \\
\hline \multicolumn{2}{|l|}{$\begin{array}{l}\text { Cáncer activo o no controlado } \\
\text { Infección por virus de inmunodeficiencia humana } \\
\text { Alteraciones psiquiátricas } \\
\text { Infecciones bacterianas o virales activas } \\
\text { Pacientes con corta expectativa de vida }\end{array}$} \\
\hline
\end{tabular}




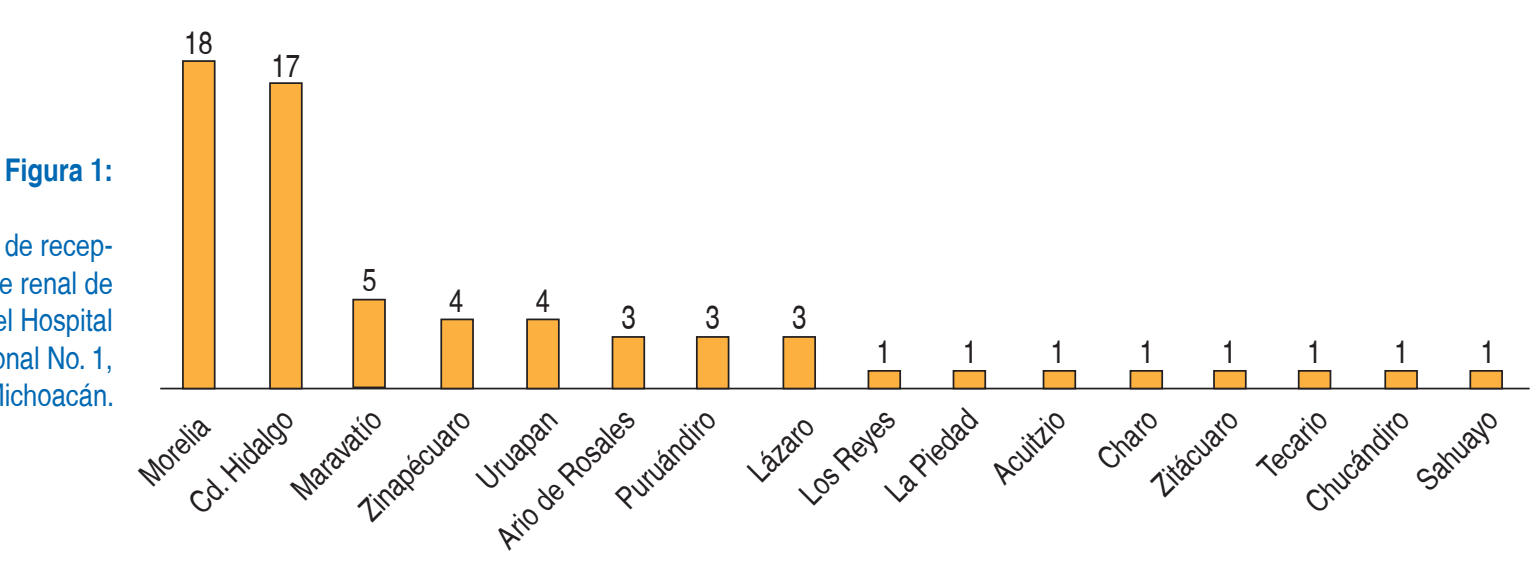

Lugar de origen de receptores de trasplante renal de donante vivo en el Hospital General Regional No. 1 Charo, Michoacán

a alguna terapia de reemplazo renal (prediálisis). El tiempo promedio de terapia de reemplazo renal fue de 20.4 meses (Tablas 2 y 3).

La relación de los donadores vivos con los receptores y la cantidad de haplotipos compartidos se muestra en la Tabla 4. El porcentaje de reactividad de anticuerpos (PRA) fue menor de $15 \%$.

La inmunosupresión en todos los pacientes se llevó a cabo con basiliximab, prednisona, ácido micofenólico y tacrolimus, incluyendo a los que compartían dos haplotipos con su pareja.

La supervivencia global del paciente fue de $100 \%$ a uno, tres, seis, 12 y 24 meses, y de $98 \%$ a 60 meses (cinco años). Sólo hay reporte de un paciente fallecido a los 34 meses posteriores a la realización del trasplante renal y por causas externas a padecimiento renal y/o relacionado con enfermedad renal, con injerto funcional (accidente automovilístico) (Figura 2).

La supervivencia del injerto fue de $98 \%$ a un mes y a dos años, y de $94 \%$ a cinco años. Se han reportado sólo cuatro pérdidas del injerto, a un mes, a 26, 28 y 34 meses, respectivamente, $(6 \%)$. Las causas de pérdida de injerto fueron: una por trombosis arterial, otra por rechazo crónico humoral, una más por rechazo crónico por falta de consumo de medicamentos inmunosupresores y la última por la defunción del receptor renal (Figura 3).

\section{DISCUSIÓN}

Se habla de una evolución sobre la supervivencia del injerto como del paciente trasplantado renal hacia la mejora en porcentajes de estas mismas.

Se han reportado gran cantidad de artículos de investigación sobre distintos hospitales a nivel mundial con resultados en supervivencias equiparables a los obtenidos en este trabajo.

En España, en 2005, en el Hospital Clínico de Bar- celona, se reportó por Altes Ineva y colegas, durante el periodo de 1999 a 2004, una supervivencia del injerto de 97.55 y $86 \%$ a uno y cuatro años, así como la supervivencia del paciente para el mismo periodo de tiempo de 100 y $96.3 \%$ a uno y cuatro años (un paciente fallecido por causa neoplásica, con injerto funcional). ${ }^{16}$

En Bolivia, lo investigado en 2011 por Torrez Salazar y su equipo, en el Hospital Obrero No. 2 de la Caja Nacional de Salud, se reporta una supervivencia del injerto con donante vivo de 97,77 y $37 \%$ a uno, cinco y 10 años. ${ }^{17}$

En Chile fue investigada en 2014 la supervivencia del injerto y del receptor renal de un hospital por Rodríguez Vidal y colaboradores en dos periodos de tiempo, de 1994 a 2003 y 2004 a 2012; con supervivencia del paciente trasplantado de $96,90,86$ y $72 \%$ a uno, tres, cinco y 10 años en el primer periodo y de 95 y $90 \%$ a uno y tres años y $87 \%$ para cinco y 10 años durante el

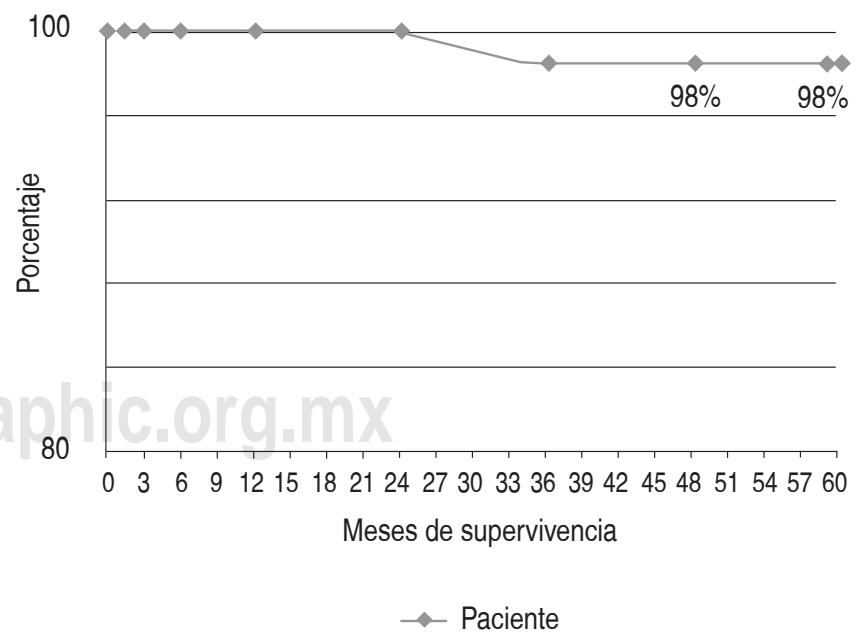

Figura 2: Supervivencia de pacientes con trasplante renal de donante vivo en el Hospital General Regional No. 1, Charo, Michoacán. 
segundo periodo. La supervivencia del injerto fue de 87,8279 y $59 \%$ a uno, tres, cinco y 10 años durante el primer periodo y de $83,77,68$ y $64 \%$ a los mismos años durante el segundo periodo de tiempo. De las cuales, las infecciones fueron la primera causa de muerte del paciente y las complicaciones quirúrgicas la principal causa de pérdida del injerto. ${ }^{10}$

\section{En México:}

- En el Hospital San José-Tecnológico de Monterrey reportado por Soltero Reyes y su grupo, durante dos periodos de tiempo, de 1975 a 1989 y de 1990 a 2001, se calculó la supervivencia del injerto a un año de $45 \%$ para el primer periodo y de $89 \%$ para el segundo periodo. ${ }^{18}$

- En el Hospital de Especialidades «Dr. Antonio Fraga Mouret», CMN «La Raza», IMSS, en el año 2010, investigado por Ticona-Garrón y colegas, se muestra la supervivencia del injerto de 83.9 y $94.3 \%$ a 12 meses tanto de donantes fallecidos como de donantes vivos, mientras que la supervivencia del paciente fue de 90.3 y $96.9 \%$ para ambos grupos. ${ }^{19}$

- En el Hospital Regional de Veracruz, según lo reportado por Hérnandez-Jiménez y colaboradores, en 2012, la supervivencia global del paciente fue de $94.9,93.4,82.3 \%$ a uno, tres y cinco años, respectivamente. Mientras que la supervivencia global del injerto fue de $87.6,79.7$ y $61.5 \%$ a uno, tres y cinco años. ${ }^{13}$

- En el Hospital de Alta Especialidad de Veracruz, analizado en 2016 por Martínez-Mier y su equipo, la supervivencia global del paciente fue de 94.7,

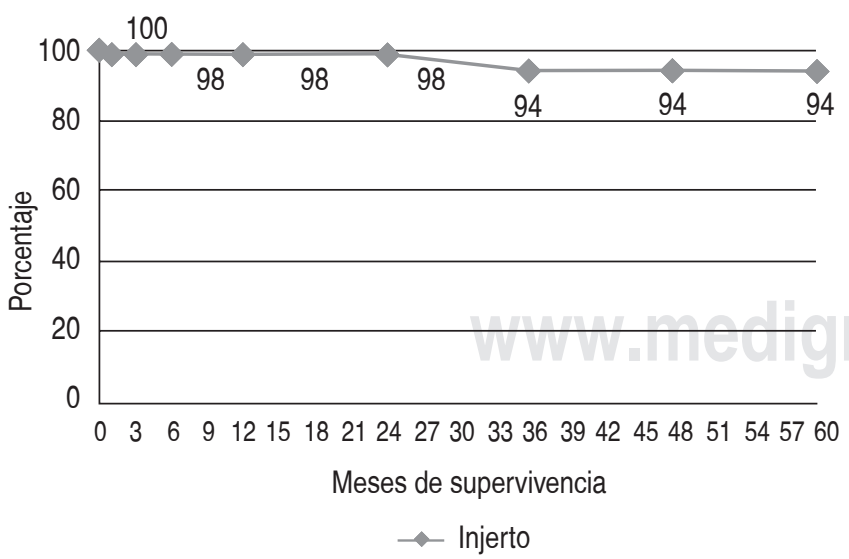

Figura 3: Supervivencia del injerto renal en pacientes receptores de donante vivo en el Hospital General Regional No. 1, Charo, Michoacán.
85.2 y $77.9 \%$ a uno, cinco y 10 años, y la supervivencia global del injerto fue de $87.2,59.7$ y $43.8 \%$ a uno, cinco y 10 años, respectivamente, con diferencia significativa entre los receptores de donante vivo contra los de donante fallecido. ${ }^{14}$

Como se observa, y afirmando lo ya planteado, ambas supervivencias han aumentado de manera considerable a través del tiempo, no sólo por avances tecnológicos, sino también por la introducción de nuevos fármacos inmunosupresores que han permitido reducir la tasa de rechazo agudo y mejorar la supervivencia del injerto a largo plazo. Al mismo tiempo, la combinación de estos fármacos ha contribuido a disminuir la tasa de fracaso tardío del injerto. El conocimiento de las causas y los factores de riesgo que conducen a la pérdida del aloinjerto deben dirigir a una intervención precoz sobre los factores de progresión, tanto inmunes como no inmunes, para prevenir dicho fracaso. Los factores relacionados con el donante son determinantes mayores de la supervivencia del injerto renal.

La continua modificación en las características demográficas y la comorbilidad de los donantes y receptores obliga a monitorear de forma continua los resultados del trasplante. Hasta la actualidad no disponemos de modelos predictivos con suficiente precisión para determinar la supervivencia del injerto a largo plazo. ${ }^{12}$

Nuestras supervivencias se equiparan con las mundiales y se han obtenido mejores resultados que los mostrados en algunos estudios, aun hablando que se tratan de resultados de un hospital de segundo nivel de atención. Nuestros resultados con supervivencia global del paciente de $100 \%$ a dos años y de $98 \%$ a cinco años, y supervivencia del injerto de $98 \%$ a un mes y dos años, y de $94 \%$ a cinco años, respectivamente, con sólo cuatro pérdidas de injerto de los 65 trasplantes realizados hasta diciembre de 2019, apoyan la necesidad de plantear características específicas en pacientes candidatos a trasplante renal.

La selección de pacientes es necesaria, y lo es más en pacientes próximos a trasplantarse en un hospital de segundo nivel, debido a la carencia en materia de infraestructura e insumos y recursos, como fármacos inmunosupresores, con las que cuentan estas unidades de salud, con el fin de mantener o aumentar los porcentajes en supervivencias tanto de pacientes trasplantados como de injertos renales.

Es por esta razón la osadía de este estudio: demostrar las características como criterios de inclusión (Tabla 4) para la selección de pacientes a trasplantar y 
donadores vivos con bajo riesgo inmunológico, en un hospital de segundo nivel y continuar con los éxitos en ambas supervivencias y disminuir las tasas de rechazo tanto agudo como crónico de injerto renal.

\section{CONCLUSIONES}

Nuestros resultados evidencian que la supervivencia del paciente y del injerto en un hospital de segundo nivel son equiparables con los hospitales de tercer nivel. La selección de pacientes en este tipo de unidades médicas es importante, por los recursos y la infraestructura con la que se cuenta; por lo que trabajar sobre pacientes con bajo riesgo inmunológico garantiza una mejor tasa de éxito en ambas supervivencias y, por consecuencia, una mejor calidad de vida.

\section{BIBLIOGRAFÍA}

1. Levey AS, Eckardt KU, Tsukamoto Y, Levin A, Coresh J, Rossert $\mathrm{J}$ et al. Definition and classification of chronic kidney disease: a position statement from kidney disease: improving global outcomes (KDIGO). Kidney Int. 2005; 67: 2089-2100.

2. Levey AS, Atkins R, Coresh J, Cohen EP, Collins AJ, Eckardt $\mathrm{KU}$ et al. Chronic kidney disease as a global public health problema: Approaches and initiatives-a position statement from kidney disease improving global outcomes. Kidney Int. 2007; 72: 247-259.

3. USRDS. ESRD in the United States. USRDS Annual Data Report. 2015; 2 (13): 291-334.

4. Lastiri Quiros HS. Enfermedad renal crónica en México: una política nacional de salud todavía pendiente. En: Tamayo y Orozco JA, Lastiri Quirós HS. La enfermedad renal crónica en México. Hacía una política Nacional para enfrentarla. 1era edición. México: Intersistemas; 2016. pp. 01-16.

5. Centro Nacional de Trasplantes. Sistema Informático del Registro Nacional de Trasplantes. [Internet]. [Consultado el 25 Marzo 2019]. Disponible en: http://www.cenatra.gob.mx.

6. Global Observatory on Donation and Transplantation. GODT [Internet]. [Consultado el 25 Marzo 2019]. Disponible en: http:// www.transplant-observatory.org/who-ont/.

7. Bochicchio Riccardelli T. El trasplante renal en México: panorama de nuestra realidad. En: Tamayo y Orozco JA, Lastiri Quirós HS. La enfermedad renal crónica en México. Hacía una política Nacional para enfrentarla. 1era edición. México: Intersistemas; 2016. pp. 63-71.

8. Domínguez-Gil B, De la Oliva VM, Escobar EM, Cruzado JM, Pascual J, Fernández FG. Situación actual del trasplante renal de donante vivo en España y otros países: pasado, presente y futuro de una excelente opción terapéutica. Nefrología. 2010; 30(Suppl 2): 03-13.

9. Gamarra G, Gomez J. Rechazo en pacientes con trasplante renal. Acta Médica Colombiana. 1991; 16 (5): 244-255.

10. Rodríguez Vidal M, Parra Morales M, Rocha Ortiz S et al. Supervivencia del injerto y del receptor en el trasplante renal en el Hospital Guillermo Gran Benavente (Concepción, Chile). Enferm Nefrol. 2014; 17 (4): 292-298.

11. Seija M, Nina M, Astesiano R, Coitiño R, Santiago J, Ferrari $S$ et al. Rechazo agudo del trasplante renal: diagnóstico y alternativas terapéuticas. Nefrol Latinoam. 2017; 14 (4): 119130.

12. Moreso F, Hernández D. ¿Ha mejorado la supervivencia del injerto tras el trasplante renal en la era de la moderna inmunosupresión? Nefrología. 2013; 33 (1): 14-26.

13. Hernández-Jiménez JD, Hernández-Navarrete LS, RodríguezFernández A, Jiménez-López LA, Varela-Pérez V, IrigoyenCastillo $A$ et al. Experiencia a largo plazo del programa de trasplante renal del Hospital Regional de Veracruz, México. Rev Mex Traspl. 2012; 1 (1): 15-21.

14. Martínez-Mier G, Ávila-Pardo SF, Irigoyen-Castillo A, RodríguezFernández A, Jiménez-López LA, Varela-Pérez V. Análisis de la supervivencia a 10 años de trasplante renal en el Hospital de Alta Especialidad de Veracruz. Rev Mex Traspl. 2016; 5 (3): 113-119.

15. Centro Nacional de Trasplantes. Desarrollo de la donación y los trasplantes en Michoacán: Antecedentes históricos; Los inicios. Detrasplantes. 2008; número especial: 2-5.

16. Altes IM, Alonso PP, Abadia H, Izquierdo RL, Oppenheimer F, Álvarez VR. Evolución del trasplante renal de donante vivo: datos históricos, estadísticos, nacionales y propios. Arch Esp Urol. 2005; 58 (6): 497-501.

17. Torrez SJ, Torrez SJ, Espinoza DE, Gutiérrez MJ. Sobrevida del injerto en pacientes con trasplante renal en un centro hospitalario. Gac Med Bol. 2011; 34 (2): 87-90.

18. Soltero RL, Carbajal SH, Rodríguez MC, Valdés CA. Experiencia de dos épocas del programa de trasplante renal (TR) en el Hospital San José Tec de Monterrey. Avances. 2003; 1 (1): 6-9.

19. Ticona-Garrón AB, Álvarez-Rangel LE, Jiménez-Domínguez A, Cruz-Santiago J, Medina-Uicab C, Meza-Jiménez G et al. Supervivencia del paciente e injerto renal al año de trasplante de donante fallecido; comparación con resultados de donante vivo. Rev Mex Urol. 2010; 70 (6): 347-353.

Correspondencia:

Daniela Radilla-Ramos

Calle Tenerife Núm. 360,

Fracc. Rincón de Altozano, 58350,

Morelia, Michoacán, México.

Celular: 4431092656.

E-mail: dra.danielaradilla@gmail.com 